\title{
The effect of thiopentone on somatosensory evoked responses and EEGs in comatose patients
}

\author{
T GANES, T LUNDAR \\ From the Laboratory of Clinical Neurophysiology and the Department of Neurosurgery, The National \\ Hospital, University of Oslo, Oslo, Norway
}

SUMMARY EEGs and somatosensory evoked responses from the brachial plexus, neck and scalp were recorded in seven comatose patients on continuous thiopentone infusion. Although pathological in five of the patients, the evoked responses were present in all. Additional amounts of thiopentone producing a full suppression of all spontaneous EEG activity had no effects either on the configuration of the evoked responses or on the central conduction times. This resistance of the somatosensory evoked responses to a deep and sustained thiopentone narcosis makes it a useful test in comatose patients receiving this treatment.

Evoked responses have proved valuable for determining the level and cause of coma and also to predict the final outcome of the comatose condition. ${ }^{1-12}$ Although the evidence of the value of massive barbiturate treatment in comatose patients has been conflicting, ${ }^{13}$ the treatment is in wide use and has complicated the interpretation of the evoked responses, since this drug has effects both on the visual $^{14-17}$ and cortical somatosensory evoked potentials. ${ }^{14}$ 18-25 $^{2}$ Further, the clinical neurological examination of patients on continuous thiopentone infusion is of questionable value, since the drug effects can mimic most of the signs caused by coma of cerebral origin. The EEG is of minimal help since even small amounts of barbiturates have a profound effect on the records. ${ }^{26-28}$ It is therefore of value to determine whether any of the evoked responses are sufficiently resistant to thiopentone narcosis to be used as a clinical diagnostic test. In the present study the peripheral, cervical and cortical somatosensory evoked responses (SEP) were recorded and compared to the EEG records in seven comatose patients on thiopentone narcosis. No attempts were made to evaluate the prognostic value either of the SEP test or thiopentone narcosis. The purpose of the study was to test the sensitivity of the evoked responses and of the central conduction time to a relatively long lasting deep thiopentone narcosis so

Address for reprint requests: Dr T Ganes, the Department of Neurology, The National Hospital, University of Oslo, Oslo 1, Norway.

Received 10 May 1982 and in revised form 5 November 1982. Accepted 18 December 1982 as to determine whether the SEP test could be reliably applied also in this group of intensive care patients.

\section{Materials and methods}

The seven patients examined in the present study were taken from a larger series of comatose patients treated in the neurosurgical intensive care unit.

Treatment with thiopentone was started mainly to prevent an expected rise in the intracranial pressure, and was initiated either when the patient was admitted to the intensive care unit or in a local hospital. The drug (thiopentone-Na $5 \mathrm{~g} / 1$ in $5 \%$ glucose) was administered by continuous intravenous infusion. The infusion rate was guided by the cerebral perfusion pressure (CPP). Additional thiopentone was either given as several slowly administered bolus injections or by increasing the infusion rate. Serum levels of thiopentone were determined regularly several times a day. During the barbiturate treatment the patients were artificially ventilated and the $\mathrm{PaCO}_{2}$ were kept within $3.5-5.4 \mathrm{kPa}$ whenever possible. The intracranial epidural pressure (EDP) was constantly monitored with a minitransducer placed epidurally through a burr hole in the right parietal region. ${ }^{29}$

Arterial blood pressure was recorded with a fluid pressure transducer and together with the EDP continuously displayed on a multichannel pen recorder. An indication of the cerebral perfusion pressure (CPP) thus was available throughout the intensive care period. The mean arterial blood pressures were above $100 \mathrm{~mm} \mathrm{Hg}$ and the cerebral perfusion pressures (CPP) were above $50 \mathrm{~mm} \mathrm{Hg}$ in all patients when the SEPs and EEGs were recorded. The patients' temperatures were actively kept within $36-38^{\circ} \mathrm{C}$ throughout the intensive care period.

Recording and stimulation The EEG was recorded with 
an eight channel Elema Schönander mingograph. Somatosensory evoked potentials (SEP) were simultaneously recorded from the brachial plexus (Erb's point), the neck at C5-level, and the scalp projection of the postrolandic hand area. The common reference electrode was placed on the forehead. The recording electrodes were commercially available $\mathrm{Ag} / \mathrm{AgCl}$ skin electrodes. The analogue signals were recorded and simultaneously averaged on a Medelec MS 6 electrophysiological system.

The median nerves either in the wrist or in the elbow were used for stimulation, stimulation frequency was $3 \mathrm{~Hz}$. Generally 300-500 analogue signals were averaged. High and low pass filters in the amplifiers were set to $16 \mathrm{~Hz}$ and $3.2 \mathrm{kHz}$ respectively in all channels. The signal latencies were determined with an adjustable electronic marker and were always measured from the stimulus artifact to the peak negativity of the responses. The central conduction time was determined as the peak interval between the cervical (N13) and first negative cortical responses (N20). Central conduction times above $7.2 \mathrm{~ms}$ were regarded as abnormal, as were cortical response with an N20 amplitude less than $1 \mu \mathrm{V} .^{30} 31$

\section{Results}

EEG and somatosensory evoked responses (SEP) generally were taken on the second day after admission to the neurosurgical intensive care unit. The main data of the patients are given in the table. The EEG pattern as well as the corresponding thiopentone level varied considerably at this first examination (table). In three of the patients the EEG consisted of high voltage continuous slow wave activity while four patients had more or less pronounced "suppression-burst" pattern EEG consisting of periods with low voltage records interrupted by "bursts" of relatively high amplitude The results failed to show any consistent relation between the thiopentone level and the individual EEG pattern (table) although increasing blood levels of the drug always reduced the EEG activity towards an isoelectric trace in individual patients. The somatosensory evoked responses recorded from the brachial plexus (N9), neck (N13) and scalp (N20) invariably were present in all patients. The cortical responses (N20) although present in all were of abnormally low amplitude $(<1 \mu \mathrm{V})$ in four patients (table) and the central conduction time (N13-N20) prolonged (above $7.2 \mathrm{~ms}$ ) also in four patients. The SEP test was normal in two patients (UH and AV) throughout their intensive care period. Two examples of the initial EEG records and SEP tests are given in fig $1 \mathrm{~A}-\mathrm{D}$. The corresponding thiopentone serum level are given above the respective EEG records (fig 1A, C).

Comparison of the SEP test abnormalities and the EEG records of the patients failed to show any consistent relationship (table). When additional thiopentone was administered, the effect on the EEG was rapid with slowing of the records and development of long suppression periods. The duration of the suppression periods varied from 3-7 minutes. When the drug administration was finished a "typical" suppression burst pattern with shorter periods of suppression (seconds) developed in all patients. The amount of thiopentone giving the long suppression periods varied considerably from patient to patient. SEP taken during the period with full suppression of all spontaneous EEG activity invariably failed to show any changes either in signal morphology or central conduction times (table). Two examples of SEP tests during full EEG suppression are given in fig $2 \mathrm{~A}-\mathrm{D}$. The records were

Table Effect of thiopentone on EEG pattern and central conduction time (N13-N20)

\begin{tabular}{|c|c|c|c|c|c|c|c|c|}
\hline \multirow[t]{2}{*}{ Initials } & \multirow{2}{*}{$\begin{array}{l}\text { Age } \\
(y r)\end{array}$} & \multirow[t]{2}{*}{ Diagnosis } & \multicolumn{3}{|c|}{ First examination } & \multicolumn{3}{|c|}{ After additional thiopental } \\
\hline & & & $\begin{array}{l}\text { Serum } \\
\text { thiopentone } \\
\text { umolll }\end{array}$ & $E E G$ & $\begin{array}{l}S E P \\
N 13-N 20\end{array}$ & $\begin{array}{l}\text { Serum } \\
\text { thiopentone } \\
\text { umolll }\end{array}$ & $E E G$ & $\begin{array}{l}\text { SEP } \\
N 13-N 20\end{array}$ \\
\hline TA & 14 & Head injury & 87 & $\begin{array}{c}\text { Suppression } \\
\text { bursts }\end{array}$ & $\begin{array}{r}7 \cdot 3^{*} \\
\dagger\end{array}$ & 122 & $\begin{array}{l}\text { isoelectric } \\
\text { EEG }\end{array}$ & $7 \cdot 3^{*}$ \\
\hline $\begin{array}{l}\text { AV } \\
\text { EL }\end{array}$ & $\begin{array}{l}12 \\
23\end{array}$ & $\begin{array}{l}\text { Cardiac arrest } \\
\text { Head injury }\end{array}$ & $\begin{array}{r}76 \\
212\end{array}$ & $\begin{array}{l}\text { Delta/theta } \\
\text { Suppression } \\
\text { bursts }\end{array}$ & $\begin{array}{l}6.5^{*} \\
\dagger\end{array}$ & $\begin{array}{l}158 \\
298\end{array}$ & $"$ & $\begin{array}{l}6 \\
8 \cdot 5^{*}\end{array}$ \\
\hline TF & 17 & $\begin{array}{l}\text { Gun shot, } \\
\text { brain injury }\end{array}$ & 170 & Delta/theta & $6 \cdot 1 \dagger$ & 204 & " & $6 \cdot 6$ \\
\hline OT & 34 & Head injury & 118 & $\begin{array}{l}\text { Suppression } \\
\text { bursts }\end{array}$ & $7 \cdot 5^{*}$ & 307 & $"$ & $7 \cdot 5^{*}$ \\
\hline MH & 9 & Strangulation & 136 & Theta/delta & $10 \cdot 1^{*}$ & 156 & $"$ & $10 \cdot 3^{*}$ \\
\hline UH & 21 & $\begin{array}{l}\text { Massive intra- } \\
\text { ventricular } \\
\text { haemorrhage } \\
\text { from AVM }\end{array}$ & 124 & $\begin{array}{c}\text { Suppression } \\
\text { bursts }\end{array}$ & 7 & 178 & " & 7 \\
\hline
\end{tabular}

*Pathologically prolonged values (above $7.2 \mathrm{~ms}$ )

†Indicates which patients had pathological cortical responses (N20 lower than $1 \mu \mathrm{V}$, or abnormal response cenfiguration). 
(A) OT

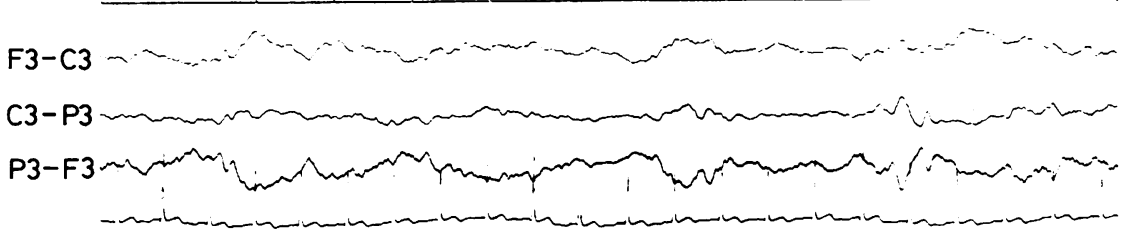

F4-

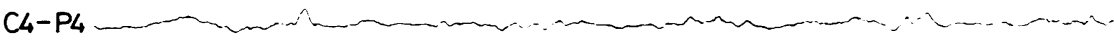

$P_{4}-F_{4}$

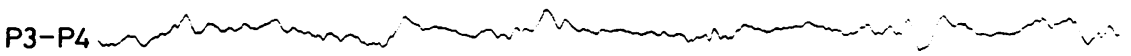

$[100 \mu \mathrm{V}$
(B)

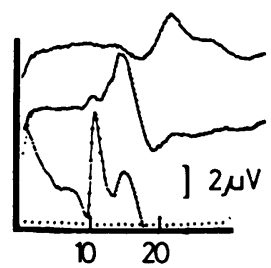

(C) U.H.

$124 \mu \mathrm{mol} / 1$
(D)

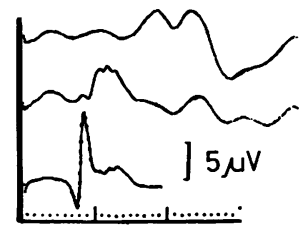

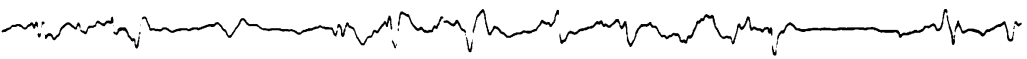

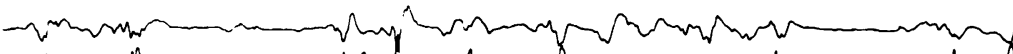

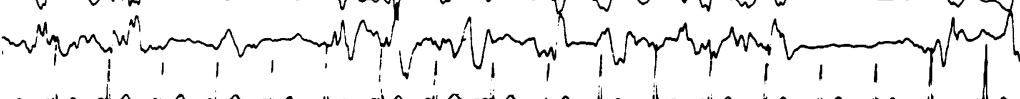

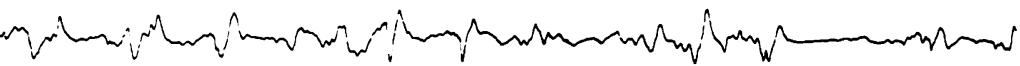

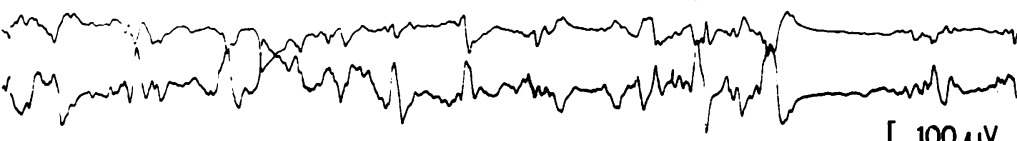

Fig 1 The EEGs $(A, C)$ and SEP records $(B, D)$ from two of the patients taken after 48 hours of deep thiopentone narcosis. The actual thiopentone serum levels are given above EEG records in $A$ and $C$. Time scale for the EEG records (1 $s$ between vertical lines) is given in the uppermost records in $A$ and $C$. The records in $B$ and $D$ represent plexus (lower), cervical (middle) and cortical (upper) evoked responses, Time scale in ms.

taken from the same two patients shown in fig 1 A-D. Serum thiopentone levels are given above the respective EEG records.

\section{Discussion}

Previous human and experimental studies have demonstrated that barbiturate anaesthesia abolishes the later components of the cortical somatosensory evoked response while having relatively little effect on the earlier waves. ${ }^{1418-25}$ These data were confirmed in the present study, showing that the first negative wave (N20) of the cortical response as well as the cervical (N13) and peripheral plexus (N9) evoked responses were present in all patients on sustained thiopentone narcosis. The N20 of the cortical response probably represents the first postsynaptic response to the thalamo-cortical volley, while the cervical evoked response evidently consists of synaptic as well as non-synaptic subcomponents generated in the cervical medulla. ${ }^{32} \mathrm{~N} 9$ represents the peripheral action potentials in the brachial plexus fibres. ${ }^{313}$ The fact that deep thiopentone narcosis had no effect on either of these responses or the "conduction time" between them, thus indicates that impulse transmission in the fast conducting dorsal column-lemniscal afferent pathway was resistant to large amounts of thiopentone. Corresponding results from human and animal data have been previously reported..$^{18-253435}$ The mechanism for the relative "insensitivity" of this system to barbiturates is not clear, but it may be related to the organisation of this particular afferent system with the few and powerful excitatory synapses involved. ${ }^{21}$ The effect of barbiturates on the central nervous system is mainly inhibitory, the inhibition partly being produced by enhancing the effect of inhibitory synapses. Barbiturates also have a more pronounced 
(A) $O T$

F3-C3
C3-P3
P3-F3
F4-C4
C4-P4
P4-F4
P3-P4 $307 \mu \mathrm{mol} / \mathrm{l}$

\section{(307}

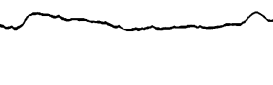

1

\section{(C)}

UH

$178 \mu \mathrm{mol} / 1$
(B)

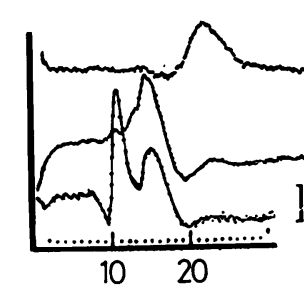

$[50 \mu \mathrm{V}$

\section{$[50 \mu \mathrm{V}$}

Fig 2 The EEGs $(A, C)$ and SEP records $(B, D)$ of the same two patients as in fig 1 after additional amounts of thiopentone. The actual thiopentone serum levels are given above EEG records in $A$ and $C$. Time scale for the EEG records (1 s between vertical lines) is given in the uppermost records in $A$ and $C$.

inhibitory effect on multisynaptic pathways than on pathways with one or few synapses involved..$^{2134-40}$

Since no EEG records were taken prior to thiopentone administration, it was not possible to decide to what extent the prevailing "brain injury" contributed to the initial EEG patterns. The fact that the SEP test was pathological in five of the patients examined, either with a reduced amplitude of $\mathrm{N} 20$ or with a prolonged central conduction time (N13-N20), however, evidently reflected the presence of a brain injury or ischaemia rather than thiopentone narcosis. The two patients (AV and $\mathrm{UH}$, table) with normal responses and conduction times throughout their intensive care periods as well as the general lack of effect on the SEP test in all patients when additional thiopentone was administered further gave support to this assumption. The present data also demonstrated that amounts of thiopentone sufficient to suppress fully all spontaneous EEG activity for several minutes had no effect on the somatosensory evoked responses or conduction times. Whether the responses would remain unchanged during a longer period with isoelectric EEG is unknown. However, Trojaborg and Jørgensen ${ }^{11}$ have shown that the cortical somatosensory evoked response may persist and be well preserved (and indicate a relative good prognosis) in comatose patients with a totally isoelectric EEG. Furthermore, experimental data indicate that no qualitative physiological or biochemical changes occur in the brain at anaesthetic levels sufficient to produce a sustained isoelectric EEG. ${ }^{41-43}$ Massive doses of thiopentone producing long lasting isoelectric EEG have failed to reveal any toxic effects on the central 
nervous system ${ }^{41}$ and have been used with some success in intensive care medicine. ${ }^{44}$ It is therefore unlikely that even a long lasting thiopentone induced suppression of spontaneous EEG activity would produce any major changes in the somatosensory evoked responses. Evidence favouring this hypothesis is further given by experimental data showing that although spontaneous unit activity may be fully depressed during barbiturate anaesthesia, the neurons were still able to respond to afferent stimuli. 343540

Clinical and prognostic evaluation of patients in thiopentone narcosis is generally difficult, being limited by all the restraints encountered when patients have to be examined while in deep narcosis. EEG offers little help in this situation other than being a monitor of the anaesthetic level. Moreover, the variability in this relation between the individual EEG changes and the actual serum level of thiopentone makes the judgement even more complex.

Brain stem evoked potentials (BAER) have been used with some success in comatose patients and are relatively resistant to anaesthetics. ${ }^{8}$ However, Goldie $e t a l^{2}$ have reported that $52 \%$ of the patients in coma had normal BAER, and in general there was no correlation between the BAER of these patients and the clinical outcome. ${ }^{2}$ Visual evoked responses are unreliable in patients on thiopentone narcosis since the response morphology as well as the latencies are subject to changes during anaesthesia. ${ }^{1617}$

In conclusion we therefore feel that the present somatosensory evoked responses, including the central conduction times, offer a valuable test in evaluating the comatose intensive care patients in thiopentone narcosis.

\section{References}

' Azinska BJ, Cracco RQ. Short latency somatosensory evoked potentials in brain dead patients. Arch Neurol 1980;37:222-5.

${ }^{2}$ Goldie WD, Chiappa KH, Young RR. Brain stem auditory evoked responses and short latency somatosensory evoked responses in the evaluation of deeply comatose patients. Neurology (Minneap) 1979;29: 581-2.

${ }^{3}$ Greenberg RP, Becker DP, Miller JD, Mayer DJ. Evaluation of brain function in severe human head trauma with multimodality evoked potentials. J Neurosurg 1977;47:163-77.

${ }^{4}$ Hume AL, Cant BR, Shaw NA. Central somatosensory conduction time in comatose patients. Ann Neurol 1979;5:379-84.

${ }^{5}$ Lindsay KW, Carlin J, Kennedy I, Fry J, McInnes A, Teasdale GM. Evoked potentials in severe head injury-analysis and relation to outcome. J Neurol Neurosurg Psychiatry 1981;44:796-802:
- Starr A. Auditory brain stem responses in brain death. Brain 1976;99:543-4.

${ }^{7}$ Starr A, Achor LJ. Auditory brain stem responses in neurological disease. Arch Neurol 1975;32:761-8.

${ }^{8}$ Stockard JJ, Stockard JE, Sharbrough FW. Brainstem auditory evoked potentials in neurology: methodology interpretation, clinical application. In: Aminoff MJ, ed. Electrodiagnosis in Clinical Neurology. New York: Churchill-Livingstone, 1980:370-413.

9 Symon L, Hargadine J, Zamirski M, Branston N. Central conduction time as an index of ischemia in subarachnoid haemorrhage J Neurol Sci 1980;35:211-24.

${ }^{10}$ DeLa Torre JC, Trimble JL, Beards RT, Hanlon K, Surgeoun JW. Somatosensory evoked potentials for the prognosis of coma in humans. Exp Neurol 1978;60:304-17.

11 Trojaborg W, Jørgensen EO. Evoked cortical potentials in patients with isoelectric EEGs. Electroencephalogr Clin Neurophysiol 1973;35:301-9.

12 Uziel A, Benezech J. Auditory brain stem responses in comatose patients: relationship with brainstem reflexes and levels of coma. Electroencephalogr Clin Neurophysiol 1978;45:515-23.

${ }^{13}$ Aitkenhead AR. Do barbiturates protect the brain. $\mathrm{Br} J$ Anaesth 1981;53:1011-3.

${ }^{14}$ Clark DL, Rosner BS. Neurophysiological effects of general anaesthetics. 1. The electroencephalogram and sensory evoked potentials in man. Anesthesiology 1973;38:564-82.

15 Bergamesco B. Modification of cortical responsiveness in humans induced by drugs acting on the central nervous system. Electroencephalogr Clin Neurophysiol 1967;23:191.

${ }^{16}$ Domino EF, Corssen G, Sweet RB. Effects of various anaesthetics on the visually evoked responses in man. Anesth Analg Curr Res 1963;42:735-47.

${ }^{17}$ Domino EF. Effects of preanaesthetics and anaesthetic drugs on visually evoked responses. Anesthesiology 1967;28:184-97.

${ }^{18}$ Abrahamian HA, Allison T, Goff WR, Rosner BS. Effects of Thiopental on human cerebral evoked responses. Anesthesiology 1963;24:651-7.

19 Albe-Fessard D, Besson JM, Abdelmoumene M. Action of anaesthetic on somatic evoked activities. Int Anesthesiol Clin 1970;8:129-64.

${ }^{20}$ Allison T, Goff WR, Abrahamian HA, Rosner BS. The effects of barbiturate anaesthesia upon human somatosensory evoked responses. Electroencephalogr Clin Neurophysiol 1963;Suppl 24:68-75.

${ }^{21}$ French JD, Verzeano M, Magoun HW. A neural basis for the anaesthetic state. Arch Neurol 1953;69:519 23.

${ }^{22}$ Ikuta T. Effects of Thiopental on the human somatosensory evoked response. Folia Psychiatr Neurol Jpn 1966;20:19-31.

${ }^{23}$ Rosner BS, Goff WR, Allison T. Properties of cerebral somatic evoked responses in unanaesthesized Cebus monkey. Electroencephalogr Clin Neurophysiol 1963;24:43-54.

${ }^{24}$ Shagass C, Schwartz M, Amadeo M. Some drug effects on evoked cerebral potentials in man. J Neuropsychiatry 1962;3. Suppl. 1 S49-S58. 
${ }^{25}$ Yamamoto S, Schaeppi U. Effect of pentothal on neural activity in somatosensory cortex and brain stem in cat. Electroencephalogr Clin Neurophysiol 1961;13:24856.

${ }^{26}$ Brazier MAB, Finesinger JE. Action of barbiturates on cerebral cortex. Electroencephalographic studies. Arch Neurol 1945;53:51-8.

${ }^{27}$ Kiersey DK, Bickford RG, Faulconer A Jr. Electroencephalographic patterns produced by Thiopental sodium during surgical operations. Description and classification. Br J Anaesthesiol 1951;23:141-52.

${ }^{28}$ Martin TT, Faulconer A, Bickford RG. Electroencephalography in anaesthesiology. Anesthesiology 1959;20:359-76.

${ }^{29}$ Nordnes J, Serck-Hansen F. Miniature transducers for intracranial pressure monitoring in man Acta Neurol Scand 1970;46:203-14.

${ }^{30}$ Ganes T. A study of peripheral, cervical and cortical evoked potentials and afferent conduction times in the somatosensory pathways. Electroencephalogr Clin Neurophysiol 1980;49:446-51.

${ }^{31}$ Ganes T. Somatosensory conduction times and peripheral, cervical and cortical evoked potentials in patients with cervical spondylosis. J Neurol Neurosurg Psychiatry 1980;43:683-9.

${ }^{32}$ Ganes T. Synaptic and non-synaptic components of the human cervical evoked response. J Neurol Sci 1982;55:313-26.

${ }^{33}$ Jones SJ. Short latency potentials recorded from the neck and scalp following median nerve stimulation. Electroencephalogr Clin Neurophysiol 1977;43:85363.

${ }^{34}$ King EE, Naquet R, Magoun HW. Action of pentobar- bital on somatic afferent conduction in the cat with special reference to the thalamic relay. J Pharmacol Exp Ther 1955;113:31.

${ }^{35}$ Rosner BS, Clark DL. Neurophysiological effects of general anaesthetics. II. Segmental regional actions in the brain. Anesthesiology 1973;39:59-81.

${ }^{36}$ Barker JL, Mae Huang LY, McDonald JF, McBurney RN. Barbiturate pharmacology of cultured mammalian neurons. In: Raymond Fink B, ed. Molecular Mechanisms of Anaesthetics. New York: Raven Press, 1980;79-93.

${ }^{37}$ Larsen MD, Major MA. The effect of hexobarbital on the duration of the recurrent IPSP in cat motoneurons. Brain Res 1970;21:309-11.

${ }^{38}$ Nicoll RA. Pentobarbital: action on frog motoneurons. Brain Res 1975;96:119-23.

${ }^{39}$ Nicoll RA, Eccles JC, Oshima T, Rubia F. Prolongation of hippocampal inhibitory postsynaptic potentials by barbiturates. Nature 1976;258:625-7.

${ }^{40}$ Shapovalov AI. Intracellular microelectrode investigations of effect of anaesthetics on transmission of excitation in the spinal cord. Fed Proc (Translation suppl.) 1964;1 part II: 113-6.

${ }^{41}$ Michenfelder JD. The interdependence of cerebral functional and metabolic effects following massive doses of Thiopental in the dog. Anesthesiology 1974;41:231-6.

${ }^{42}$ Michenfelder JD, Milde JH, Sundt TM Jr. Cerebral protection by barbiturate anaesthesia. Arch Neurol 1976;33:345-50.

${ }^{43}$ Steen PA, Michenfelder JD. Neurotoxicity of anaesthetics. Anesthesiology 1979;50:437-53.

${ }^{44}$ Rosenthal MH, Larson CP. Protection of the brain from progressive ischemia. Western J Med 1978;128:145. 